\title{
Investigation of Students' Satisfaction about H5P Interactive Video on MOODLE for Online Learning
}

\author{
Kamran Mir \\ Assistant Director, \\ ICT, Allama Iqbal Open University \\ kamran.mir@aiou.edu.pk \\ Muhammad Zafar Iqbal \\ Assistant Professor \\ EPPSL, Allama Iqbal Open University \\ mzafar.iqbal@aiou.edu.pk
}

\author{
Jahan Ara Shams (Corresponding Author) \\ Assistant Professor \\ ECE \& ETE, Allama Iqbal Open University \\ jahanara.shams@aiou.edu.pk
}

\begin{abstract}
Open universities play an important role in delivering distant learning education to the general public. MOODLE is an open-source programme that enables and maintains the success of open universities. One of the main concerns of teachers when using internet content is the students' interest, particularly when using recorded videos because synchronous interactive instruction is not possible for big groups of students online. In an elearning system, interactive videos are crucial because they allow learners to interact with learning content while watching the video. The H5P module of MOODLE Learning Management System (LMS), was used to generate an interactive film in this empirical study. The focus of the study was to investigate students' satisfaction about interactive video content on MOODLE in online learning. It was assessed by using the Delone and Mclean Information Systems Success Model. H5P interactive video content was developed and implemented on MOODLE and satisfaction of students was measured. The findings revealed that the value of video for learning effectiveness is depending on the level of interactivity. Students in the e-learning class with interactive video had much higher levels of satisfaction than students in other settings.
\end{abstract}

Keywords: H5P Interactive Video, MOODLE, Online Learning, Students' Satisfaction

\section{Introduction}

Quality Education is one of the United Nations' sustainable development goals, which entails "ensuring inclusive and equitable quality education for all and encouraging lifelong learning opportunities for all" (United Nations (UN), 2015). Formal educational institutes are attempting to attain this goal of quality education, but the formal education system is insufficient and incapable of meeting the challenge of ensuring inclusivity and equity in education. To meet this issue, open and remote learning universities play a critical role in expanding people's access to education and encouraging lifelong learning.

Open and Distance Learning (ODL) is the type of education system in which student needs not to attend the regular classes at university/institute. The learning process usually takes place without the learner's physical meet up with the tutor (Moore, Dickson-Deane, \& 
Galyen, 2011). This is useful when face-to-face learning is not possible for the learner, or the available resources are not enough to meet the expenses of physical learning. This mode of learning has gained popularity especially after COVID-19 pandemic situation. This makes the distance learning a different area as compared with formal education system where both the student and tutor need to be physically present. ODL is an emerging area where many approaches are applied to improve the overall quality of the system. The quality of this system needs continuous improvement as the learner and tutor are physically far away. Thus, the transactional distance needs to be removed or minimized. Overall improvement needs the deployment of advance technologies and innovative strategies. Continuous growth of ODL has created many opportunities for educators, researchers, tutors and students (Dabbagh \& Bannan-Ritland, 2005).

Much research has been undertaken to investigate the challenges and issues that students in ODL encounter from the perspective of the institution, and many technological solutions to those problems have been proposed in these studies. (Mir, 2017) emphasised the necessity of systemic assistance for ODL students and proposed an online integrated student support system to alleviate ODL students' administrative issues. According to (Beldarrain, 2006), scholars are always worried about the challenges that distance educators and students confront, which must be solved using evolving tools and technologies. The relationship between technology and learning in distance education has been proved by research (Dabbagh \& Bannan-Ritland, 2005).

Emerging technologies such as Web 2.0 are allowing distant educators and learners to interact in real time, increasing the efficiency and overall efficacy of ODL. When these technologies are used, they will alter existing learning models while simultaneously creating new ones and assigning new roles to students and teachers. Chickering and Ehrmann (1996) examined the problem and proposed some ODL principles, such as quick communication between the learner and the tutor, prompt feedback, and quick delivery without focusing on the delivery method, which will be difficult to achieve without the use of innovative tools and techniques.

Due to the geographic distance between the student and the educator, the use of a Learning Management System (LMS) becomes required in ODL. Since many ODL institutions have embraced and implemented it, interest in using it as a Virtual Learning Environment (VLE) or Learning Management System (LMS) for eLearning is growing. In comparison to face-to-face students, ODL students encounter greater administrative and technical issues. The success of a learning management system (LMS) can be measured using the Information System (IS) success model.

DeLone and McLean's information system success (ISS) model, according to Wu and Wang (2006), is a multi-dimensional model applied in a variety of domains. The concept of evaluating the success of information systems, on the other hand, is still in its infancy. There are six dimensions in this model. The Delone and Mclean ISS Model was used to guide this research, which considers system quality, information quality, service quality, user satisfaction, intention to use, and net benefits. The validity and reliability of the model was recently demonstrated (Sirsat \&Sirsat, 2016). Each of the model's dimensions has been briefly explained below.

The first is the System Quality Measurement, which focuses on the system's usability as well as the system's performance characteristics. Access, convenience, customisation, data accuracy, ease of learning, simplicity of use, reaction speed, reliability, interactivity, system accuracy, and system features, among other things, are all aspects of system quality. The second metric is Information Quality, which is more closely linked to production. The output that the user wants and the output that the information system produces. The closer these two 
are, the higher the success rate and the greater the user pleasure. Then there's the issue of service quality. Technical support or assistance supplied by the IT department is included in this measure of success factor. This could include the support team's certainty, empathy, adaptability, interpersonal quality, and responsiveness. Next, there's User Satisfaction. It refers to the amount of satisfaction with an information system. It is a critical indicator of success. User happiness is not a stand-alone metric; it is tied to other factors such as service quality. Then there's the Intention to Use. This metric represents the frequency with which the system is used or the user's intent to utilise it. Actual use, daily use, sort of use, number of transactions, and so on are all included. Last but not the least, there are net benefits. This metric is a compilation of all of the previous ones. This is linked to the mutual benefits of all parties concerned (Urbach \& Muller, 2012).

H5P is an Open Source HTML5 based module created by a community of educators to make the online learning interactive. It supports active learning, which is a proven and very popular method of teaching used in online learning. Integrating H5P contents in any online course makes it interesting and collaborative in nature. It provides the opportunity for learners to interact and critically think what they are learning on computers without physical and/or live presence of the teacher. Another great benefit with $\mathrm{H} 5 \mathrm{P}$ is that it allows you to easily share and reuse content (Singleton \& Charlton, 2020). H5P supports following interesting activities or content types:

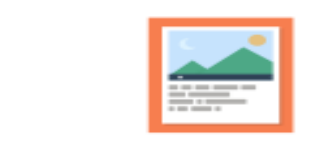

Agamotto

Create a sequence of images that gradually

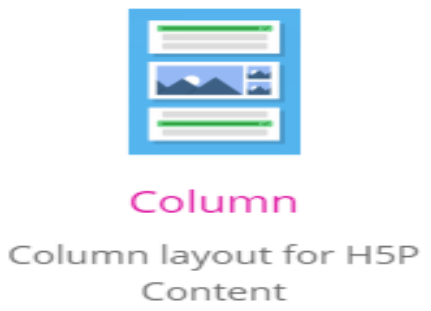

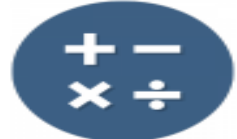

Arithmetic Quiz

Create time-based arithmetic quizzes

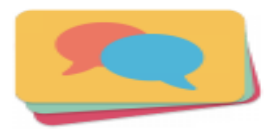

Dialog Cards

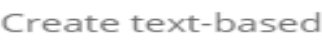

turning cards

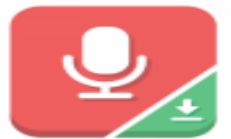

Audio Recorder

Create an audio recording

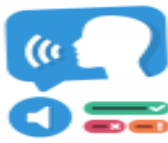

Dictation

Create a dictation with instant feedback

Figure 1: H5P Content Type Large Resources - I (https://h5p.org/)

All above activities can easily be integrated in any MOODLE course. For example, Image Hotspots can create multiple information area within a single image. The content types are not limited to above mention but also include other contents like Image pairing, Image Slider, Interactive Book and Virtual Tour (360). Rapid changes in the world's increasing technological world and distance education, as well as the acceptance of new inventions and techniques, new technologies, and approaches, are gradually displacing old technical traditions (Iqbal, Mir, \& Janjua, 2020). 


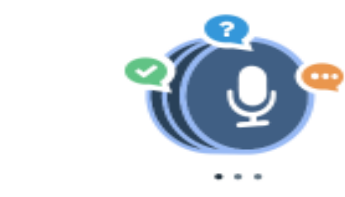

Speak the Words Set

A series of questions answered by speech

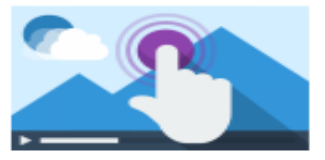

Interactive Video

Create videos enriched with interactions

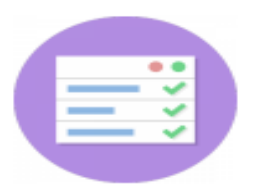

Summary

Create tasks with a list of statements

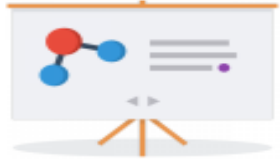

Course Presentation

Create a presentation with interactive slides

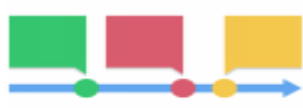

Timeline

Create a timeline of events with multimedia

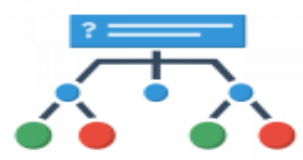

Branching Scenari...

Create dilemmas and self paced learning

Figure 2: H5P Content Type Large Resources - II (https://h5p.org/)

This HTML5-based interactive video activity allows users to add or embed an existing video and add interaction within that video for example, asking a multiple-choice question or fill in the banks during the video on a specific time. It makes the video engaging and interactive and serves the feature of synchronous class in an asynchronous/recorded video.

Keeping in view the context of online learning and H5P interactive video on MOODLE, the objective of the study was to:

- Investigate Students' Satisfaction about H5P Interactive Video on MOODLE for Online Learning

\section{Methodology}

The study was quantitative, and the design of the study was descriptive. In order to investigate the students' satisfaction level, survey method was used. Using an online questionnaire, the success aspects of MOODLE, a Learning Management System deployed at Allama Iqbal Open University (AIOU) in Pakistan, were investigated in the first phase of this study. There were seven components in the questionnaire: demographic and general information, information quality, system quality, and service quality, intention to use, user happiness, and net advantages perceived by students and teachers. The instrument's construction was based on DeLone and McLean's success model, which was modified by (Rana, Dwivedi, \& Williams, 2013). Questionnaire was placed online on the LMS for the period of one month and also shared with all the active students and tutors through different means whichever available and feasible. The survey was open for all the students and teachers of AIOU who are using or have used the MOODLE platform. 

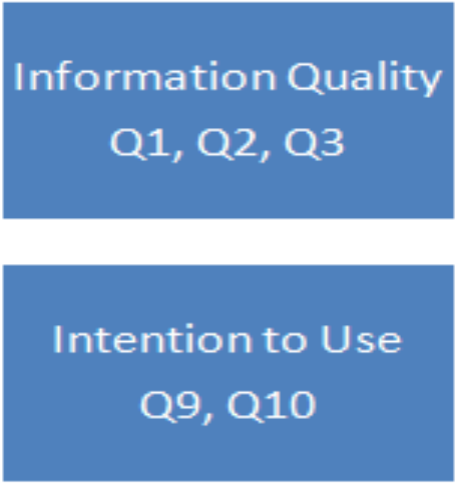
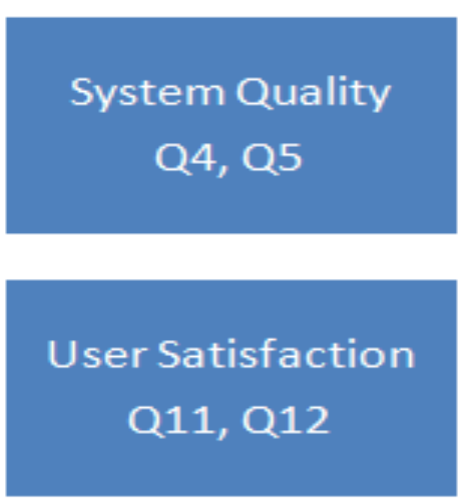
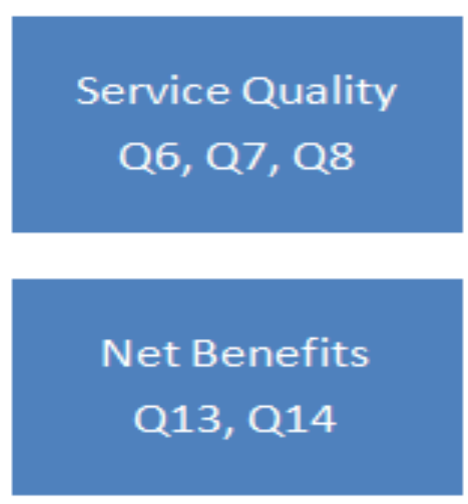

Figure 3: Success Factor Measures

Except for two open-ended questions for general remarks, all of these questions were multiple-type, closed-ended, and on seven-point Likert scale rating. For all non-demographic items, Likert scales (1-5) with rating from "Strongly Disagree" to "Strongly Agree" were used (Rana, Dwivedi, \& Williams, 2013; Rana, Dwivedi, \& Williams, 2013).

Table 1.List of Questions under each measure

\begin{tabular}{ll}
\hline Measure & Question \\
\hline $\begin{array}{l}\text { Information } \\
\text { Quality }\end{array}$ & Q2: My LMS provides very precise information that I need. \\
& Q3: My LMS provides very up-to-date information. \\
Qystem Quality & Q4: My LMS is very user-friendly. \\
& Q5: My LMS is very easy to use. \\
Q6: My LMS gives me individual/personalized attention. \\
Q7: Whenever I have a query or have to answer a query, my \\
LMS is very helpful in it. \\
Q8: I feel safe in communication while using my LMS. \\
Q9: My learning OR teaching is dependent on my LMS. \\
Q10: My frequency of using my LMS is very high. \\
\hline Q11: I am satisfied with my LMS. \\
Q12: My LMS meets my expectations.
\end{tabular}




\section{Net Benefits}

Q13:My LMS has made my learning or teaching easier.

Q14: My LMS saves me a lot of time.

In this study, H5P Interactive video content type was used to develop an interactive video, only students' satisfaction was assessed after their online learning on MOODLE using H5P interactive video content. A YouTube video on basics of Geographical Information System (GIS) was embedded overlaid by Multiple Choice Questions (MCQs) as shown in below figure. The video duration was about 4 minutes and 22 seconds and around 4 MCQs were integrated at different stages of the video. After explanation of each sub-topic, a question was asked to reinforce the concept of learning. For example, after explaining the concept of Global Positioning System (GPS), a question related to number of GPS satellites was integrated within the video to maintain the students' interactivity and attention. H5P Interactive video allows you to add multiple kinds of interactivity within the video in the form of question or additional information.

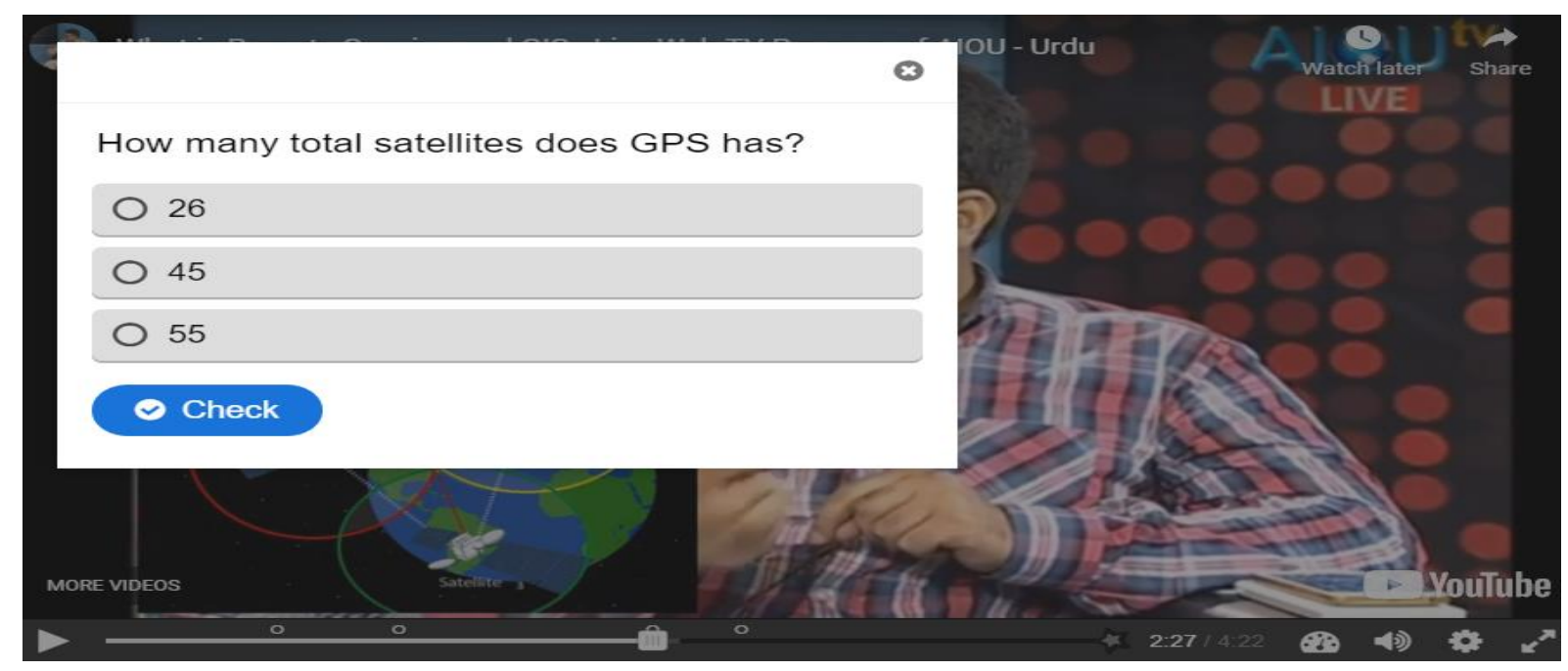

Figure 4: H5P Interactive Video

\section{Results}

\subsection{Information Quality}

This metric of success is more closely linked to output. The output that the user wants and the output that the IS produces. The closer these two are, the higher the success rate and the greater the user pleasure. 
My LMS provides very precise information that I need.

732 responses

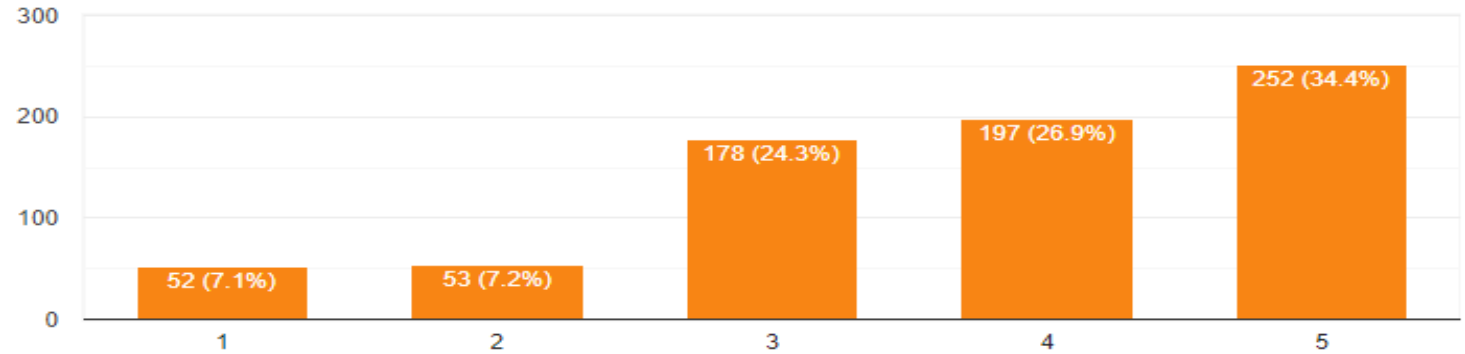

Figure 5: Students' Satifaction on Information Quality - Q1

My LMS provides very sufficient information.

732 responses

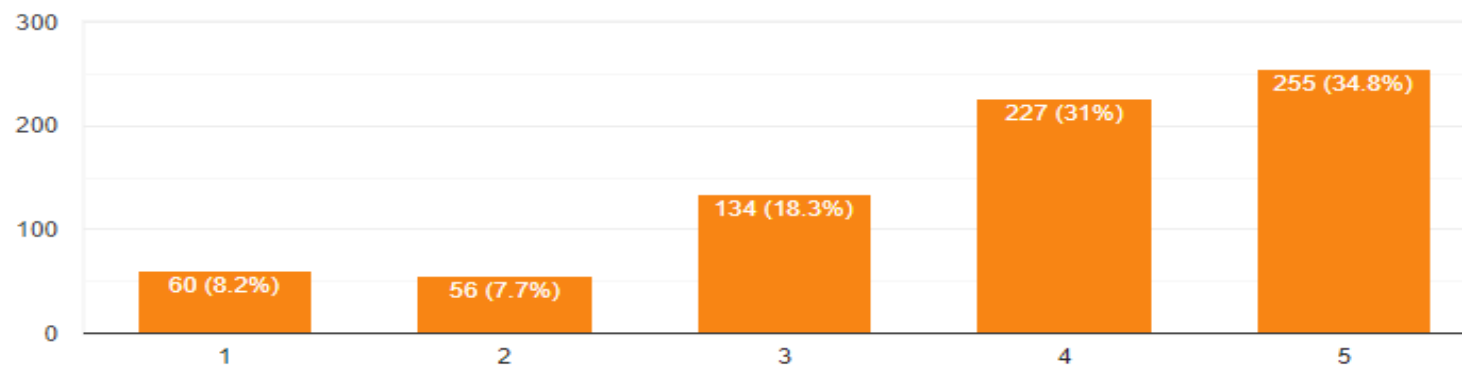

Figure 6: Students' Satifaction on Information Quality - Q2

My LMS provides very up-to-date information.

732 responses

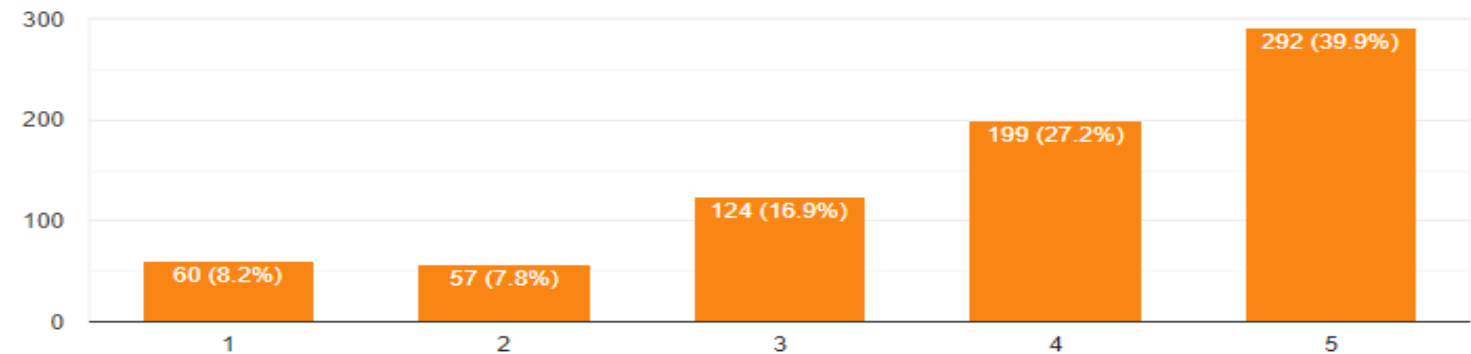

Figure 7:Students' Satifaction on Information Quality - Q3

Students' satisfaction results about information quality shows that $61 \%$ users agreed that MOODLE provides precise information what they need, 66\% users agreed that MOODLE provides sufficient information and 67\% users agreed that MOODLE provides up to date information.

\subsection{System Quality}

The System Quality Measurement focuses on the system's usability as well as the performance characteristics of the system under evaluation. Access, convenience, customisation, data accuracy, ease of learning, simplicity of use, reaction speed, reliability, 
interactivity, system accuracy, and system features, among other things, are all aspects of system quality.

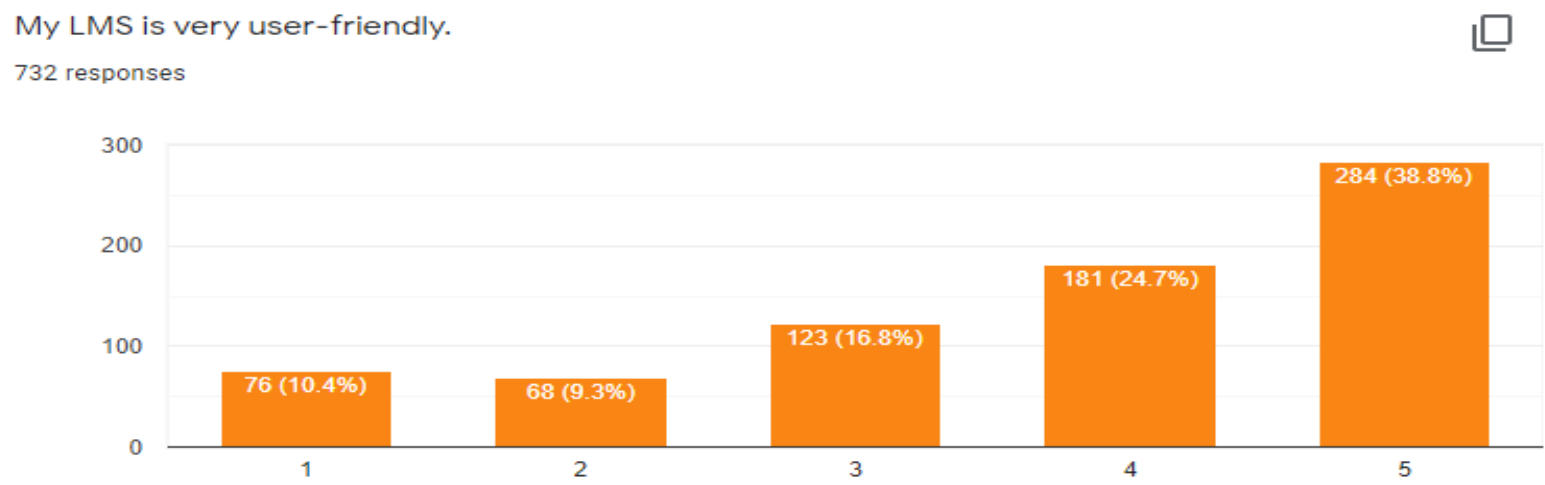

Figure 8: Students' Satifaction on System Quality - Q4

My LMS is very easy to use.

732 responses

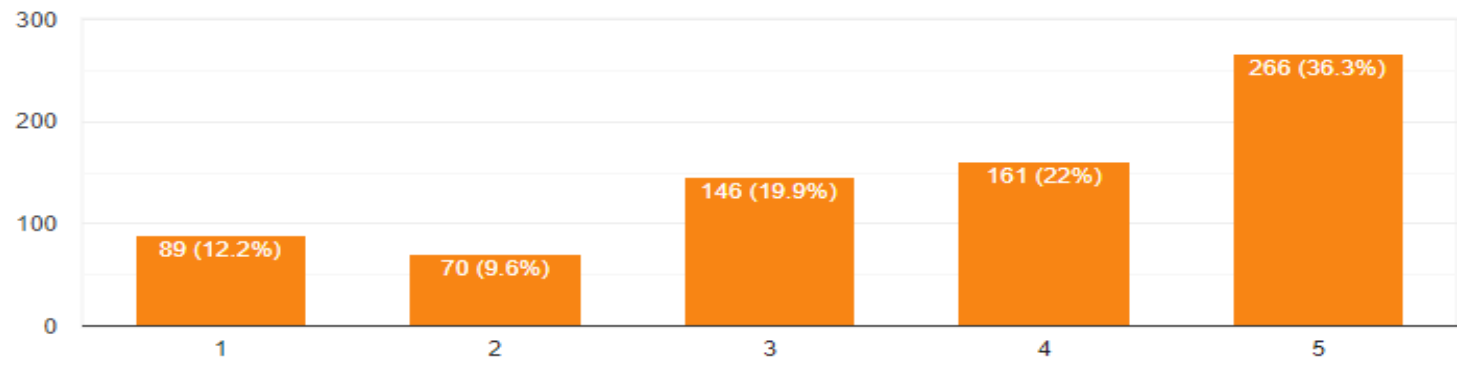

Figure 9: Students' Satifaction on System Quality - Q5

Result shows that $64 \%$ users agreed that MOODLE is user-friendly, and 58\% users agree that MOODLE is easy to use.

\subsection{Service Quality}

Technical support or assistance supplied by the IT department is included in this measure of success factor. This could include the support team's certainty, empathy, adaptability, interpersonal quality, and responsiveness.

My LMS gives me individual/personalized attention.

732 responses

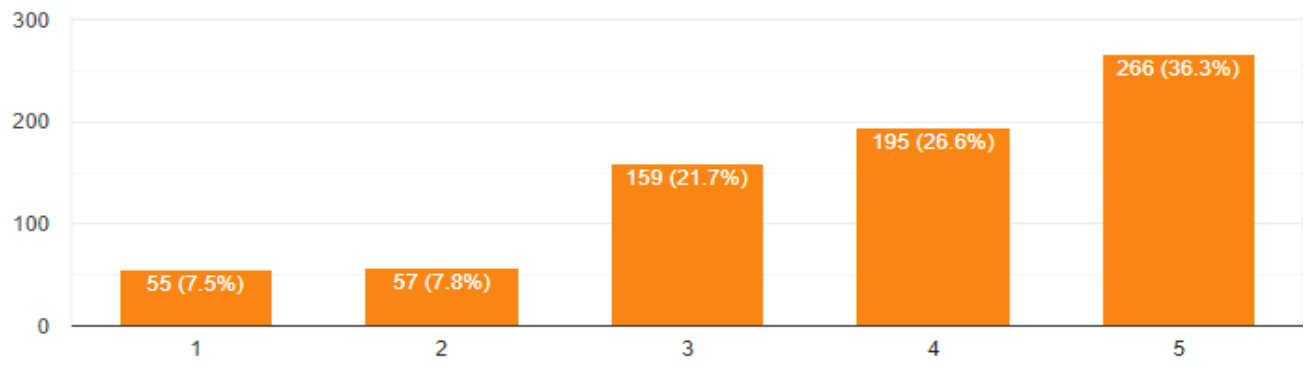

Figure 5:Students' Satifaction on Service Quality - Q6

Result shows that $63 \%$ users agree that MOODLE gives them individual or personalized attention. 
Whenever I have a query or have to answer a query, my LMS is very helpful in it. 734 responses

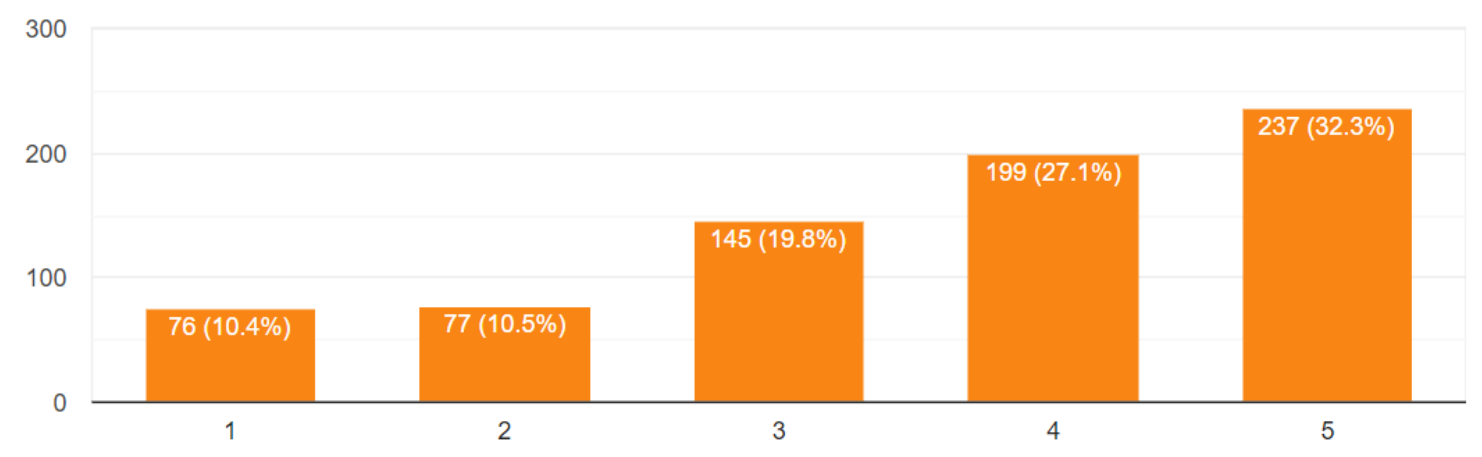

Figure 11: Students' Satifaction on Service Quality - Q7

I feel safe in communication while using my LMS.

734 responses

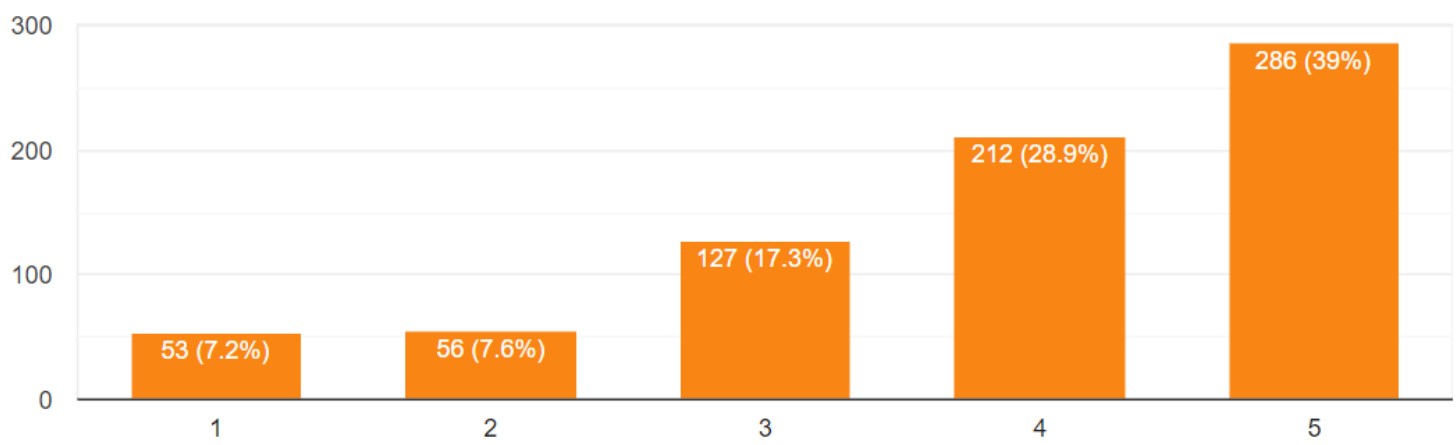

Figure 62: Students' Satifaction on Service Quality - Q8

\subsection{Intention to Use}

This metric represents the frequency with which the system is used or the user's intent to utilise it. Actual use, daily use, sort of use, number of transactions, and so on are all included.

My frequency of using my LMS is very high.

732 responses

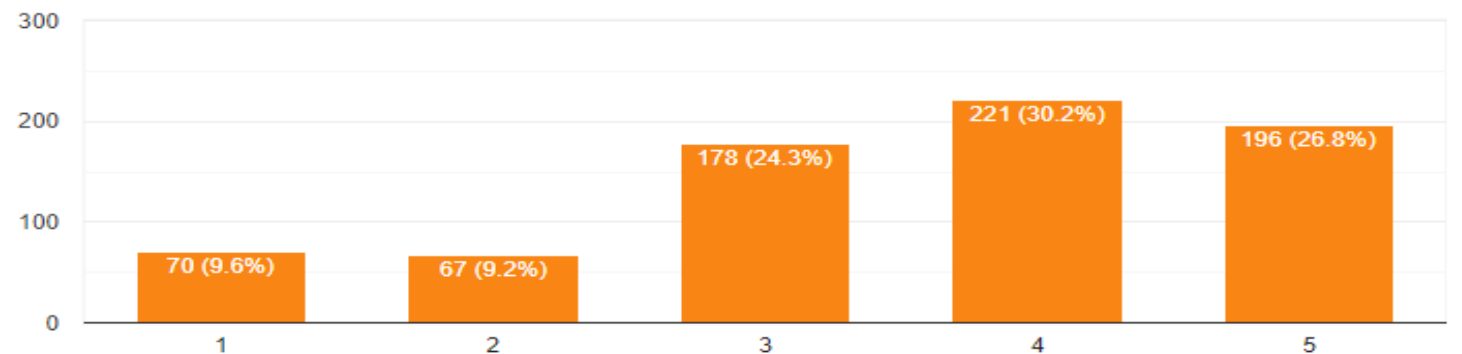

Figure 73: Students' Satifaction on Intention to Use - Q9

Result shows that $57 \%$ users agree that they frequently use MOODLE. 


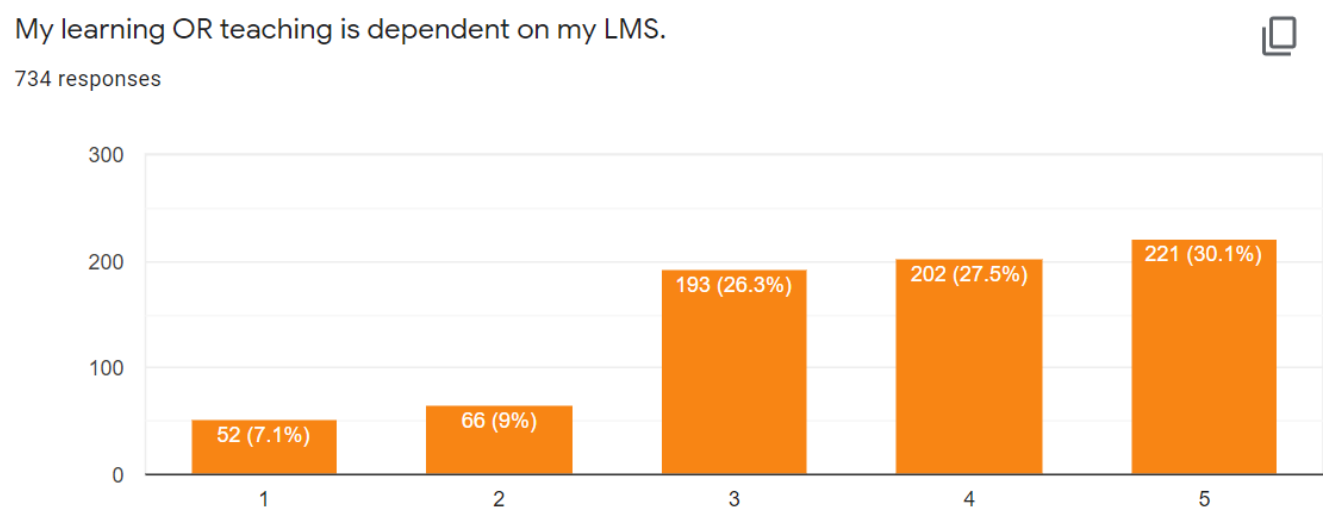

Figure 84: Students' Satifaction on Service Quality - Q10

\subsection{User Satisfaction}

It refers to the amount of satisfaction with an information system. It is a critical indicator of success. User happiness is not a stand-alone metric; it is tied to other factors such as service quality. Result shows that $59 \%$ users agree that they are satisfied with MOODLE. This parameter is however, very relative in nature and there could be multiple factors due to which user satisfaction may vary based on their personal experiences with teacher, connectivity or user experience.

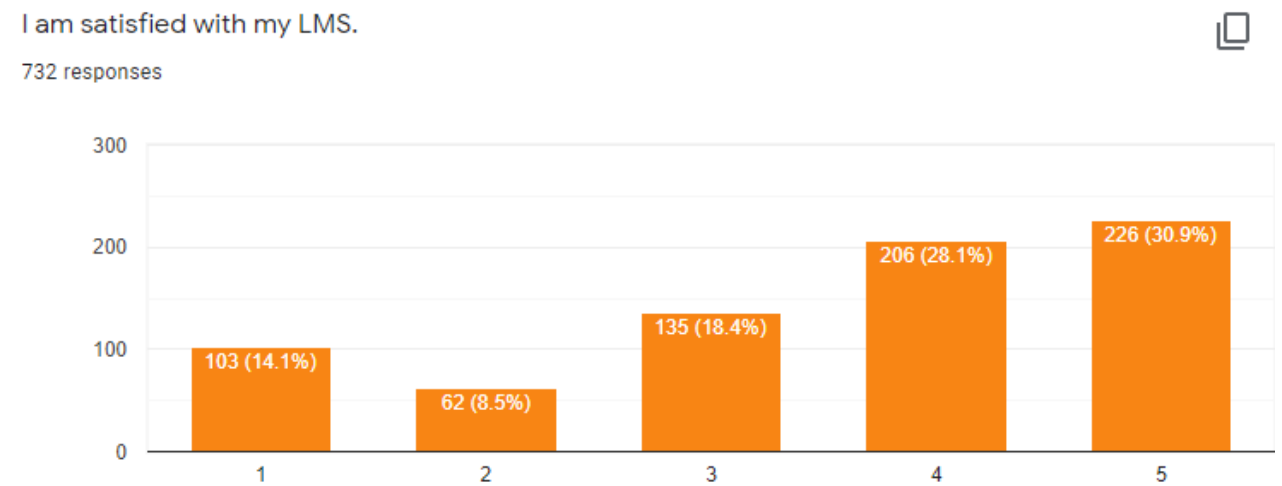

Figure 95: Students' Satifaction on User Satisfaction - Q11

My LMS meets my expectations.

734 responses

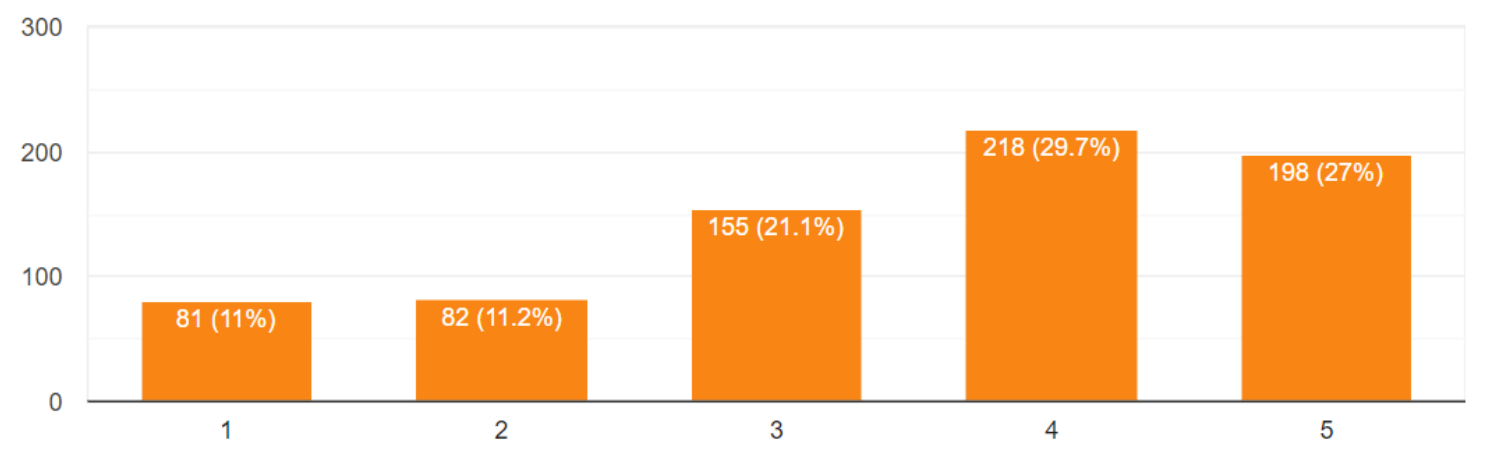

Figure 16:Students' Satifaction on Service Quality - Q12 


\subsection{Net Benefits}

This metric is a compilation of all of the previous ones. This is linked to the mutual benefits of all parties concerned. Result shows that $66 \%$ users agree that MOODLE has made their learning or teaching easier.

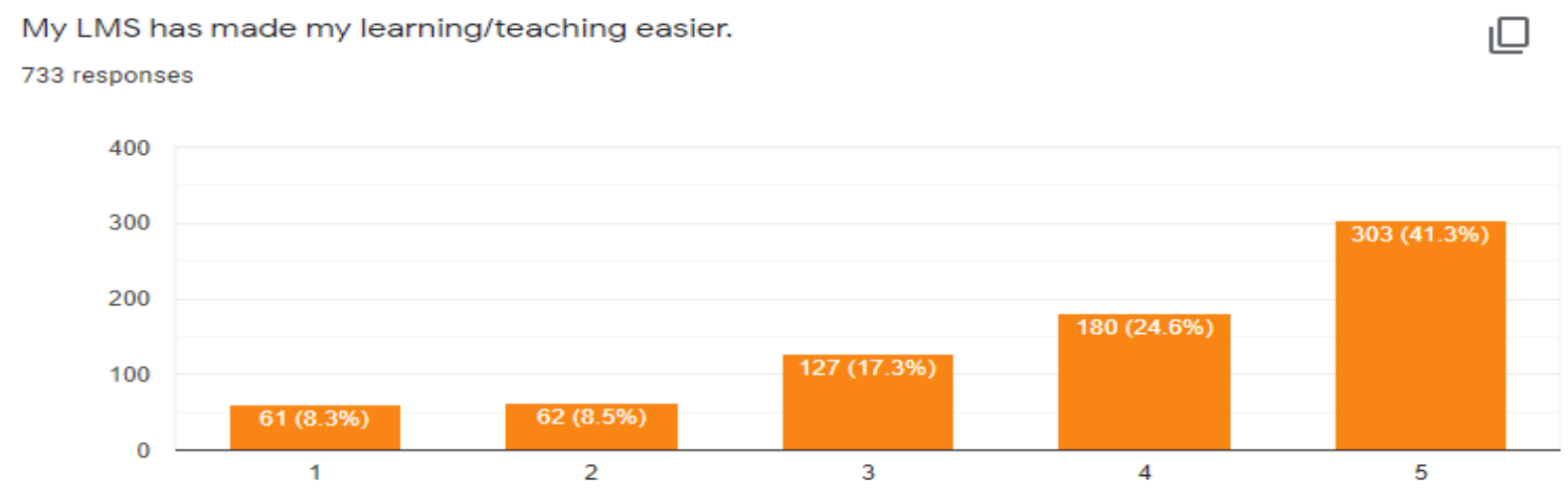

Figure 107: Net Benefits - Q13

My LMS saves me a lot of time.

734 responses

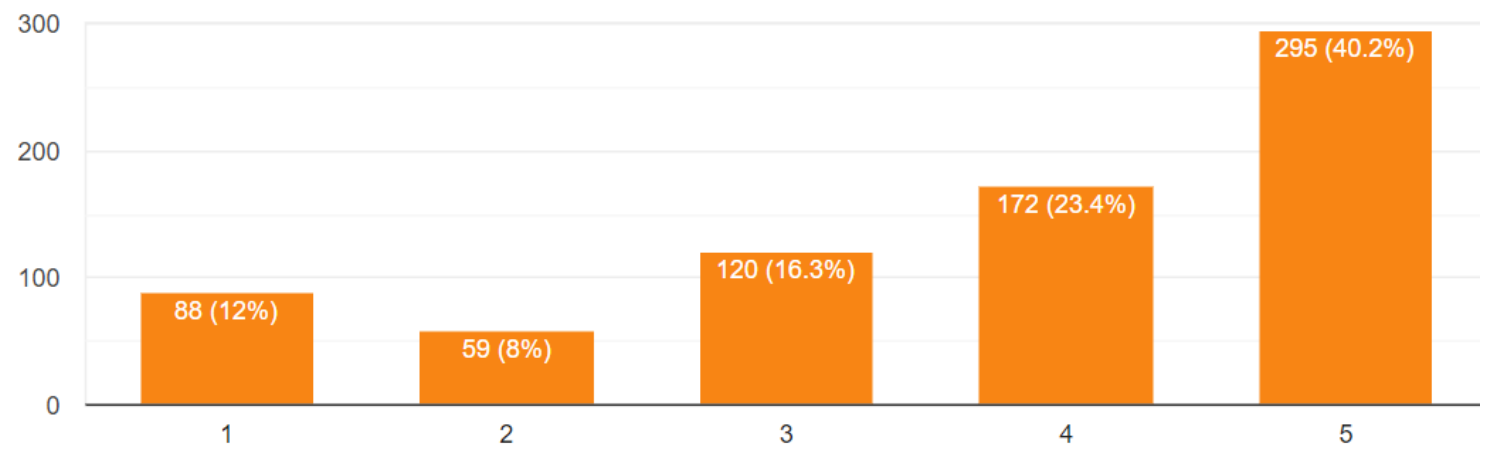

Figure 118: Students' Satifaction on Service Quality - Q14

\section{Conclusion and Recommendations}

This research shows that students were somehow satisfied with MOODLE as a Learning Management System where as their less agreement was shown in intention to use which reflects their lack of interest in the learning content. Their interest in learning can be improved by using interactive video H5P content. This study also showed that H5P is very easy to use and one can easily convert existing static or recorded video content into an interactive video content which can help in boosting the interest of the learners by engaging them in different on-spot questions while the video is running. Therefore, it was recommended to use H5P interactive video content to increase the students' engagement in learning at higher education level on MOODLE. 


\section{References}

Beldarrain, Y. (2006). Distance Education trends: Integrating new technologies to foster student interaction and collaboration. Distance Education, 27(2), 139-153.

Chickering, A. W., \& Ehrmann, S. C. (1996). Implementing the seven principles: Technology as lever. AAHE bulletin, 49(2). 3-6.

Dabbagh, N., \& Bannan-Ritland, B. (2005). Online learning: Concepts, strategies, and application. Prentice Hall.

Iqbal, M. Z., Mir, K., and Janua, S. (2020). An Examination of Open and Distance Learning Support System using Data Analytics: A Case Study of AIOU.International Journal of Distance Education and E- Learning. 5(2). 58-73.

Mir, K. (2017). Design and development of online student support system. Pakistan Journal of Distance and Online Learning, 3(1), 1-8.

Moore, J. L., Dickson-Deane, C., \& Galyen, K. (2011). e-Learning, online learning, and distance learning environments: Are they the same? The Internet and Higher Education, 129-135.

Rana, N. P., Dwivedi, Y. K., \& Williams, M. D. (2013). Evaluating alternative theoretical models for examining citizen centric adoption of e-government. Transforming Government: People, Process and Policy.

Singleton, R., \& Charlton, A. (2020). Creating H5P content for active learning. Pacific Journal of Technology Enhanced Learning, 2(1). 13-14.

Sirsat, S. S., \& Sirsat, M. S. (2016). A validation of the DeLone and McLean model on the educational information system of the Maharashtra State (India). International Journal of Education and Learning Systems, 1. 9-18.

United Nations (UN). (2015). Transforming our world the 2030 Agenda for Sustainable Development. New York: UN.

Wu, J.-H., \& Wang, Y. (2006). Measuring KMS success: A respecification of the DeLone and McLean's model. Information and Management, 43. 728-39. 